In " Hannay's Royal Almanack for 1846" we find a catalogue of patent medicines offered to the pullic for the cure of their diseases, and sold in Oxford-street, London. This catalogue, inserted at the end of the almanack, contains the names and titles of 753 different medicinal nostrums for human use, exclusive of dentifrices, of which alone there are fifty-seven.

Of the above nostrums, there are in the form of pills, 190; of lozenges, 80 ; of tinctures, elixirs, and drops, 74 ; of plasters, liniments, and ointments, 100 ; besides varions powders, balsams, liquids, \&c.

It would be useless to give a list of the diseases, for the infallible cure of which these nostrums are earnestly recom. mended. Many of them are proposed for the cure of acute diseases, as convulsions, cholera, fever, ophthalmia, \&ce; but the majority for the cure of clrronic diseases, either affecting the system generally, or the different vital organs, and many of them, when described, are separately represented as a certain remedy for a multiplicity of diseases.

As might be expected, this Oxford-street sanitarium, so abundantly supplied with all-healing materials, appears to have become also an oracle which is solicited for advice by an immense number of persons, who apply by letter, which application is required to be accompanied with a fee of a sovereign. Thus the additional impropriety is committed of prescribing for distant patients through written communicitions, without, as every honest medical man would require, a personal examination, to ascertain those vital indications and peculiar circumstances in the patient which no non-medical person can comprehend or describe, even in his own person, and according to which circumstances the treatment should be varied and regulated.

Country customers are flatteringly addressed in the opening advertisement to this voluminous catalogue of patent medicines.

Here, then, we have in the heart of the metropolis what is probably the leading establishment or emporium of quackery in the kingdom, although there are undoubtedly thousands of others on a smaller scale, not only in the capital, but throughout the provinces. And this extensive system of homicidal fraud is sanctioned, defended, and recommended by the existing laws and royal patents. Yes, this is the union of pliysic and the state! Here we have the state materia medica and the state practice of physic flourishing in the ninetcenth century in defiance of legitimate medicine, of lumanity, and of religion.

Truly the papal sale of indulgences was a trifle in point of iniquity - an innocent cheat in comparison with the vended privileges of death-dealing quackery; for we may presume that the purchasers of indulgences were more or less guilty parties, whereas the credulous victims of quackery are those afflicted in mind and body, as the anxious parent, the sickly maiden, the alarmed youth, the innocent child, whose confidence during sickness is fraudulently obtained to a reliance upon a deceitful remedy, while time neglected, aggravating the unchecked malady, or with the aid of an injurious nostrum, hurries on the victim to a stage of incurable disease, and a premature grave.

How effectually, then, does legislation operate for the production of disease, and the destruction of the sufferers-taxes on windows, - a tax on healthy ventilation, a material cause of disease among the population; and then the sarcastic promise by the quacks of health and vigour to the afflicted, proffered under the assurance of royal protection, and the more barefaced guarantee of eminent professional approbation falsely advanced.

If our porter or our snuff be adulterated, how severe are the legal penalties on the offenders; but medicine and medical advice, the only hope and resource of the sick, may be adulterated, or, what is the same thing, dispensed under falso characters, and empirical treatment be recommended by the most unblushing ignorance, not only with impunity but with positive legal encouragement.

It is not astonishing, under existing circumstanees, that this baneful system should be so engrafted on the habits of the British pnblic, for in fact the medical profession, notwithstanding its varied claims on the public for protection and reward, has been totally overlooked and neglected; the valuable public services of its most eminent members abroad and at home have not received that consideration from the government which is undoubtedly due to them. The profession itself has been allowed, for centuries, to remain in a state of con flicting chàos very-prejudicial to its public estimation, and thus by the additional means of neglecting and degrading the scientific body of the profession, has the government fostered the growth and extension of quackery.

We are naturally blind to the evils and corruptions in the midst of which we have been born and have grown up. The public, therefore, from the patronage they bestow upon this corrupt system of medicine, and the magnitude to which it has attained, are evidently insensible to its folly and impropriety; and attempts to convince them of the deceptions practised on them will undoubtedly be regarded by them as the envious efforts of a feeble profession to overthrow a successful rival-as idolatry has ever struggled against the cultivation of a true rcligion. We can see the wickedness and follies of foreign people; we shudder at the human sacrifices of the Eastern world; we decry the burning of Hindoo widows, and the immolations to the idol Juggernauth; but, at the same time, we cannot perceive, or be convinced, of the multitude of bloodless sacrifices brought to pass among ourselves, in our private chambers, by the systematic and indis. criminate use of poisonous nostruins.

It is undoubtedly one of the strongest arguments in favour of protection to the profession, and of the public safety, that even the learned and good are often blind to the evils of empirical practice, and insensible to the danger of errors and delays in the treatment of progressing disease; and the reliance of eminent individuals on quackery acts as a powerful example on hundreds of persons in this country of initators.

The spirit of philanthropy, from time to time, has made important steps in advancing the interests and welfare of mankind-as in the suppression of lotteries, of slavery, of climbing boys, \&c., and now, in the general sanitary effort to eradicate domestic pestilence from among us. Let us hope that the in creasing public intelligence in matters connected with their own welfare will lead to a speedy and vigorous effort to exterminate for ever the patent plague, quackery.-Y Yours, \&c., February, 1848.

EmLndator.

\section{FEVER FROM BAD DRAINAGE.}

To the Editor of THE LANCET.

Sir,-In The LanceT of June 3rd I reported a case of putro-adyuamic fever, in which the nature and virulence of the symptoms, and the rapidly fatal course of the malady, incicated the action of a poisonous miasm, while the latter was referred to the constant and very offensive emanations that arise from drains, connected more especially with Collegestreet and Bowling-street, Westminster. The inhabitants of these streets have long and bitterly complained of the frequency and severity of this nuisance, which, at present, is not in the slightest degree abated by the drainage operations lately undertaken. Since the publication of the case alluded to, I have seen several others (occurring in children) in these streets and immediate neighbourhood, which, although differing in degree, I believe to be the same in nature, and produced from the same source.

It appears to me imperative on the part of the sanitary commissioners to adopt, as quickly as possible, some effectual plan for improving the sewerage of this neighbourhood, and checking this prolific source of disease. The cases to which I now allude, and which fell under my own observation, were characterized by remittent fever, more or less acute, accompanied with enlargement of the lymphatic glands of the neck and face, pain and swelling of the surrounding cellular tissue, and cedena. In one case, supptration followed, and a large abscess formed in the neck. Sometimes the entire face, and the legs and feet, were cdematous, resembling dropsy after scarlet fever. The complexions of these children became anæmic-singularly pale and semi-transparent. The course of the affection is commonly tedious and wavering, with an intolerance of those remedies which usually promote convalescence, as if the system were suffering under the constant presence of a counteracting agent.

These cases appear to me sufficiently peculiar and characteristic to be attributed to a specific source; and that source, I believe, is the contaminated air of the neighbourhood in which the patients reside. The existence of this impurity, as I have said, is amply testified by a number of the inhabitants, whose sensations of health are constantly more or less dis. turbed by it. One lady, living in College-strect, states, that in her house they regularly burn a considerable quantity of tobacco, to nentralize the drain-smell which rises through. the sink in the scullery. She herself is just now recovering from a sharp attack of sickness and diarrhœe, produced apparently by this offensive cause.

I remain, $\mathrm{Sir}$, yours obediently, 